\title{
Good outcome in refractory cervical dystopia with combination of Deep Brain Stimulation on globus pallidus internus nucleus and delayed selective periphery rhizotomy with five years follow up
}

\begin{abstract}
Cervical dystonia is the most common form of focal dystonia and it has poor options for treatment like botulin toxin, Baclofen, kinesics, which most times are ineffective or have complications. As second line treatments destructive surgical procedures are currently tried first and Deep Brain Stimulation (DBS) by stereotactic implant, later. We present a case in which cervical neurology was done after DBS, with long term good results.
\end{abstract}

Keywords: cranio cervical dystonia, deep brain stimulation, dystonia, peripheral neurotomy
Volume 8 Issue 5 - 2018

\author{
Andreani Juan Carlos M, ${ }^{1,2}$ Francis NG Ariel, ${ }^{2}$ \\ Sosa Echeverría NM, ${ }^{2}$ Piedimonte Fabián \\ César ${ }^{1,2}$ \\ 'Programa Provincial de Neuro modulación de la Pcia de \\ Buenos Aires, Argentina \\ ${ }^{2}$ Fundación CENIT, Buenos Aires, Argentina
}

Correspondence: Andreani Juan Carlos M, Programa Provincial de Neuro modulación de la Pcia de Buenos Aires,

Argentina, Email jcmandreami@gmail.com

Received: April 28, 2018 | Published: October 30, 2018

\section{Introduction}

Cervical dystonia is a common presentation of segmental dystonia, and is currently manifested by involuntary sustained contractions of cervical territory and abnormal head movements or postures, visible and often palpable, what become harmful and disabling. Medical treatment of cervical dystonia often renders limited benefit and side effects are common. Dystonia can be treated by means of medication, botulinum toxin injections, and physiatry. ${ }^{1}$ In refractory cases or those who worsens with time in despite of the treatment, surgery could a valid option. ${ }^{2}$ The surgical treatment for refractory torticolis has been continuously developed with the aim of both, improvement of outcome and reduce complications. Most of destructive procedures have been less used because their current complications while some other ones have been increasingly more employed because considered safer and more effective. ${ }^{3-6}$

\section{Case report}

As far as we could know, through bibliographical search in Medline, Pubmed and other current international sources, this was the first publication that reports the effect of GPi-DBS in combination with delayed bilateral rhizotomy in cervical dystonia and we have published it in a previous paper. ${ }^{7}$ The actual presentation is the continuation of the patient's follow up.

We present a women $58 \mathrm{y}$, in the present days without hereditary history of dystonia; she developed at 52y progressive contracture of muscles of the neck and a feeling that his head was moving backwards. The symptoms were gradually exacerbating to take a stand permanent retrocollis. Treatment with levodopa and botulinum toxin injections were performed (up to $500 \mathrm{IU}$ ) without satisfactory results. Secondary causes of dystonia were discarded. As she rapidly showed disabling clinical manifestations none responding to medical therapy, a surgical approach was suggested, targeting the globus pallidus internus (GPi) nucleus.

The preoperative neurology examination was performed with Toronto Western Spamodic Torticollis Rating Scale (TWSTRS) (severity 20/disability 25/pain 17.75) and Burke-Fahn-Marsden Rating Scale (segmental 20/disability 11).

By micoregistration guided technique a quadripolar electrode (model 7428, Medtronic) was stereotactically implanted bilaterally on GPi and fixed with the Stimloc system. The Magnetic resonance images were processed with WinNeus program to identify coordinates. On a posterior step, the electrodes were connected to a pulse generator (Kinetra; Medtronic). We are currently employing this technique for the treatment of refractory cases in several movement disorders. ${ }^{8}$

In the post - operatory assessment we registered a clear improvement in the dystonic signs. Six months later, there was a $69 \%$ mean improvement in the BFMDRS total movement score what meant a $\mathrm{P}<0.031$, (Wilcoxin signed rank test). The mean BFMDRS disability score clearly improved $(\mathrm{P}<0.06)$. The total TWSTRS score improved 58\% $(\mathrm{P}<0.044)$. There were no adverse events following the procedure for surgical implant. ${ }^{7}$

Five years after, the dystonic symptoms dramatically returned despite a the correction of the stimulation parameters, so it was indicated a selective peripheral bilateral rhizotomy with Bertrand technique ${ }^{9}$ at the left side and Taira technique ${ }^{10}$ at the right, in order to reduce risks of complications on neck muscles voluntary movements.

In the immediate post - operative control, one month after surgery, the results returned to values very close as after DBS implantation. In five years of monthly follow up her clinical improvement has not significantly changed. 


\section{Discussion}

Palidum stimulation by DBS implantation is a current treatment for Spasmodic Torticolis, ${ }^{11}$ but it hasn't solved all problems related to the disease and seldom results are incomplete or worsen with time. ${ }^{12}$

Efforts are being made to improve results by means of technological advances ${ }^{13}$ and target selection. ${ }^{14}$ It is a common practice in refractory Cranio, cervical Dystonia, to perform DBS after peripheral surgery has failed, ${ }^{15}$ but not the converse, as in our case.

\section{Conclusion}

We conclude that we need more studies and long-term monitoring to determine more adequate indications for the beneficial combination of these two procedures in this sequential order, as shows the long term successful outcome in this case.

\section{Acknowledgements}

None.

\section{Conflict of interest}

Author declares that there is no conflict of interest.

\section{References}

1. Krauss JK, Toups EG, Jankovic J, et al. Symptomatic and functional outcome of surgical treatment of cervical dystonia. J Neurol Neurosurg Psychiatry. 1997;63(5):642-648.

2. William T Dauer, Robert E Burke, Paul Greene, et al. Current concepts on the clinical features, aetiology and management of idiopathic cervical dystonia. Brain. 1998;121(Pt 4):547-560.

3. Nunta-Aree S, Sitthinamsuwan B, Itthimathin P. Overview and Outcomes of Movement Disorder Surgery. Neurological Surgery. 2010;1(1):21-26.

4. Albanese A, van Hilten B, Nuttin B. Clinical Features of Dystonia and European Guideline for Diagnosis and Treatment. In: Proceedings of the Medtronic Forum for Neuroscience and Neuro Technology. 2005. p. 3-9.
5. Albanese A, Barnes MP, Bhatia KP, et al. A Systematic Review on the Diagnosis and Treatment of Primary (Idiopathic) Dystonia and Dystonia Plus Syndromes: Report of an EFNS/MDS-ES Task Force. European Journal of Neurology. 2006;13(5):433-444.

6. Brin MF, Benabou R. Cervical Dystonia (Torticollis). Current Treatment Options in Neurology. 1999;1(1):33-43.

7. Andreani JCM, Aráoz Olivos N, Piedimonte FC. Delayed peripheral cervical rizhotomy complete results of globus pallidus bilateral deep brain stimulation in a case of refractory cervical dystonia. International Neuromodulation Society 12th World Congress Neuromodulation: Medicine Evolving Through Technology. 2015.

8. Perandones C, NAráoz Olivos, GB Raina, et al. Successful GPi stimulation in genetic Parkinson's disease caused by mosaicism of alphasynuclein gene duplication: first description. J Neurol. 2015;262(1):222-223.

9. Bertrand CM. Selective Peripheral Denervation for Spasmodic Torticollis. Surgical Technique, Results, and Observation in 260 Cases. Surg Neurol. 1993;40(2):96-103.

10. Taira T, Hori T. Peripheral Neurotomy for Torticollis: A New Approach. Stereotactic and Functional Neurosurgery. 2001;77(1-4):40-43.

11. Sarubbo S, Latini F, Quatrale R, et al. Five-year follow-up of 10 patients treated with globus pallidus internus deep brain stimulation for segmental or multisegmental dystonia. Stereotact Funct Neurosurg. 2012;90(2):84-91.

12. Mehrkens JH, Bötzel K, Steude U, et al. Long-term efficacy and safety of chronic globus pallidus internus stimulation in different types of primary dystonia. Stereotact Funct Neurosurg. 2009;87(1):8-17.

13. Miyagi Y. [Early Experience with the Vercise $<$ sup $>$ TM $<$ /sup $>$ DBS System in the Treatment of Dystonic Tremor]. No Shinkei Geka. 2017;45(3):211-217.

14. Pauls KA1, Hammesfahr S, Moro E, et al. Deep brain stimulation in the ventrolateral thalamus/subthalamic area in dystonia with head tremor. Mov Disord. 2014;29(7):953-959.

15. Capelle HH, Blahak C, Schrader C, et al. Bilateral deep brain stimulation for cervical dystonia in patients with previous peripheral surgery. Mov Disord. 2012;27(2):301-304. 